\title{
DIFFERENT TYPES OF RETURN TO SCALE IN DEA
}

\author{
Juliana Benicio $^{1 *}$ and João Carlos Soares de Mello
}

Received August 06, 2018 / Accepted April 26, 2019

\begin{abstract}
The format of the efficient frontier is an important measure of technical efficiency; additionally, it determines the type of return to scale verified by the model. The classical Data Envelopment Analysis (DEA) model, CCR (Charnes et al., 1978), assumes constant returns to scale; conversely, the BCC (Banker et al., 1984) model presents a concave downward efficient frontier that presumes variable returns to scale. This study examines how different returns to scale can be revealed in DEA, considering the possibility of the existence of a concave upward efficient frontier. This kind of frontier, not yet explored by the DEA literature, can also represent viable production, seeing that an increase of the inputs causes an increase of the outputs. Considering this, a concave upward efficient frontier presents a variable return to scale, but with different characteristics from those of the concave downward BCC efficient frontier. This proposal is important because it considers the possibility of an efficient frontier that represents different samples of decision-making units (DMUs). An upward curve would better represent DMUs of smaller production scales that have increased marginal productivity but cannot act as efficiently as larger scale units.
\end{abstract}

Keywords: DEA, efficient frontier, returns to scale.

\section{INTRODUCTION}

Nonparametric models based on mathematical programming are used to measure efficiency to achieve two main goals: building efficient production frontiers and calculating their efficiency from production data to production frontier (Färe et al., 1994; Färe \& Lovell, 1978; Milioni \& Alves, 2013). The delineation of the frontier in this model characterizes the production technology used in the productive system under analysis. Data Envelopment Analysis (DEA) is a nonparametric model that aims to obtain an ex post evaluation of the relative efficiency of management activities (Banker et al., 1984). It is based on the results of Farrell's (1957) research, who formulates a measurement method to calculate all inputs and overcoming effects with index calculation (Talluri, 2000).

\footnotetext{
*Corresponding author - https://orcid.org/0000-0003-0976-3146

${ }^{1}$ Instituto Federal do Rio de Janeiro - IFRJ, RJ, Brazil.

${ }^{2}$ Universidade Federal Fluminense - UFF, RJ, Brazil.

E-mails: juliana.benicio@ifrj.edu.br, jccbsmello@id.uff.br
} 
The DEA result is the construction of an efficient production frontier, also known as envelopment, in order that the Decision Making Units (DMUs) which have the best output/input ratio are efficient and are located on this border (Charnes et al., 1996; Pindyck \& Rubinfeld, 2002). The least efficient DMUs are in an area below the border. The original DEA model, CCR (Charnes et al., 1978), builds an efficient frontier, keeping constant returns to scale (Pastor et al., 1999).

Banker et al. (1984) developed a DEA model known as BCC, which expresses the economic notion of variable returns to scale (Banker \& Thrall, 1992). This model aims to calculate efficiency considering the production scale under which the DMU operates (Banker et al., 2004). In this model, efficient DMUs do not need to provide the same virtual output/input ratio of the most productive DMU (Banker et al., 1996).

The DEA-BCC model presents an efficient convex frontier. In the case of one input and one output, the frontier is a curve with a downward concavity. This means that:

- The average productivity varies along the frontier;

- Marginal productivity always diminishes along the DEA-BCC frontier.

Podinovski (2004) questions the fact that the DEA literature is based on only one technology, as described by the DEA-BCC model, to represent the variable returns to scale. As noted by the author, the downward concavity of the DEA-BCC frontier is an example of one kind of variable return to scale, but other formats of frontiers could improve the analysis of returns to scale in the DEA model (Sueyoshi, 1999).

Considering the production function studied in Economics, the downward concavity with positive slope is the format of frontiers that express the technology of firms with a high scale of production, and, therefore, the increase of inputs will reduce the marginal productivity of outputs. Another possibility for the format of the production function, seen in Economic literature, is the upward concavity with positive slope. This format expresses the technology of firms with a low scale of production, and therefore, the increase of inputs will improve the marginal productivity of outputs. An efficient frontier with an upward concavity, for instance, is not considered in the DEA literature and, also, presents variable returns to scale (Souza \& Gomes, 2013). It has the following characteristics (Benicio \& Soares de Mello, 2015):

- The average productivity varies along the frontier;

- Marginal productivity always increases along the efficient frontier.

This kind of frontier could consider some DMUs efficient that work on a small scale of production, and therefore, cannot reach the level of efficiency of the most productive DMU. These DMUs are considered inefficient in the DEA-BCC model.

Therefore, the application of the DEA-BCC model that results in a concave downward frontier should not be the only way to verify the variable returns to scale, and the research of new efficient 
frontier models - including upward concavity - could describe different kinds of production technology to enrich the DEA literature (Podinovski, 2004).

Thus, this research explores different possible frontier formats to be applied to the DEA model. These frontiers present different types of variable returns to scale, and therefore, the model could interpret more diverse technologies. In addition, it pursues the delimitation of the scope of the DEA-BCC model, determining the complementarity of a new frontier format with an upward concavity.

\section{THE EFFICIENT PRODUCTION FRONTIER AND VARIABLE RETURNS TO SCALE}

A productive unit may create output from several inputs. However, only those combinations that can efficiently be produced are considered technologically feasible. The production possibility set (PPS) $\mathrm{T}$ is formed by all the technologically feasible combinations of input and output (Varian, 1992). Thus, the PPS T was defined considering a multiple-input $(X)$ and output $(Y)$ production, where:

$$
\{(X, Y) \| Y \text { may be produced with an } X \text { input }\}
$$

An output production is said to be technologically efficient if there is not a $y^{\prime}>y$, such that $y$ and $y^{\prime}$ belong to the PPS. That is, it is not possible to obtain more outputs with the same amount of inputs; furthermore, it is not possible to obtain the same outputs from fewer inputs (Simon \& Blume, 1994). Thus, the efficient production frontier indicates the maximum production capacity contained in the PPS. There is a graphic representation of expression (1) in Figure 1, where $T$ is all the PPS (gray area) and the production possibility frontier is represented by $y=f(x)$.

The concept of return to scale may be applied to the efficient production frontier and interprets what happens to the output when the production scale is changed (Varian, 1992). The returns to scale explain the behavior of the variation of the outputs and inputs which are used in the production (Smith, 1976; Hart, 1990; Pigou, 1910; Ricardo, 1951).

Blaug (1962) argues that Marshal's law of "Decreasing returns" brought order and meaning to classical economics theory (Hart, 1990). It states that in all productive processes, adding more of one factor of production, while holding all others constant, will at some point yield lower incremental per-unit returns. The function shown in Figure 1 could represent the Marshal law, because it first presents an upward concave function, and, thereafter, a downward concave function. Additionally, it presents variable returns throughout the function.

Debreu (1959) mathematically defines the concept which was given by Marshall (1920):

The analyzed technology presents constant returns to scale if:

$$
f(t x)=t f(x) \text { for every } t \geq 0 \text {. }
$$

The analyzed technology presents increasing returns to scale if:

$$
f(t x)>t f(x) \text { for every } t \geq 0 \text {. }
$$




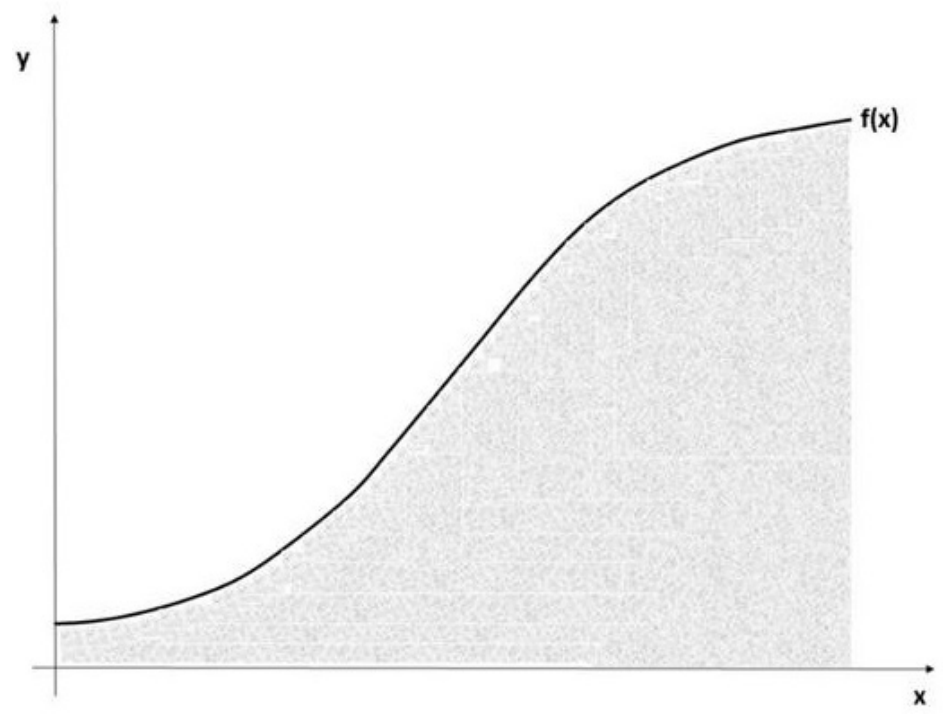

Figure 1 - The PPS T and its Efficient Frontier.

Source: The authors.

The analyzed technology presents decreasing returns to scale if:

$$
f(t x)<t f(x) \text { for every } t \geq 0 \text {. }
$$

By applying this definition along the function $y=f(x)$ as in (1), it is possible to check the return to scale at each function point.

Equivalently, at a specific point $(x, y)$ of the production function, considering the average productivity (AP) is:

$$
A P=\frac{f x}{x}
$$

It is possible to measure the type of return to scale by applying a short increase to $x$ and checking whether AP increases, decreases or remains constant (Miyazaki, 2001). So, if:

Increasing return to scale (IRS): $\triangle A P / \Delta x>0$

Decreasing return to scale (DRS): $\triangle A P / \Delta x<0$

Constant return to scale (CRS): $\triangle A P / \Delta x=0$

In case of differential production functions, we shall consider $d P M / d x$ instead of $\Delta P M / \Delta x$ (Katzner, 2006). The definition presented above is common in the classical literature and is also called local return to scale. The local return cannot be associated with any specific frontier format, that is, all three types of returns to scale can be found in both kinds of frontier: concave down or concave up. 
In addition to the concept of local return to scale, the literature has started to incorporate the concept of a global return to scale (Katzner, 2006; Miyazaki, 2001; Podinovski, 2004; Fried et al., 2008; Quinzii, 1992). The global return to scale is verified when a specific frontier format can be associated with a type of return to scale (Quinzii, 1992). Knowing that:

$$
P M g=\frac{\Delta f(x)}{\Delta x}
$$

Therefore, the global return to scale can be defined as:

Global increasing return to scale (GIRS): $\Delta P M g / \Delta x>0$

Global decreasing return to scale (GDRS): $\Delta P M g / \Delta x<0$

Global constant return to scale (GCRS): $\Delta P M g / \Delta x=0$

If $(x)$ is a differentiable function, then the following definition holds:

Global increasing return to scale (GIRS): $x^{\prime \prime}>0$

Global decreasing return to scale (GDRS): $x^{\prime \prime}<0$

Global constant return to scale (GCRS): $x^{\prime \prime}=0$

Thus, an efficient frontier presents an increasing return to scale if the marginal productivity increases or the second derivative is positive. An efficient frontier presents a decreasing return to scale if the marginal productivity decreases or the second derivative is negative. Finally, an efficient frontier presents a constant return to scale if the marginal productivity remains stable or the second derivative is zero. In the case of the non-differentiable DEA, it is not possible to verify the second derivative, but it is possible to verify the marginal productivity.

To observe the global return to scale, the efficient frontier must present only one pattern of marginal productivity variation, and the increase and decrease must be observed along the entire frontier.

\subsection{The relationship between the Global Return to Scale and the Frontier Concavity}

As shown before, the global return to scale is found when there is a standard performance in the verification of the return to scale in the production frontier; therefore, this concept is directly related to the format presented by the efficient frontier (PETRANKA, 2011).

By defining that the kind of global return to scale relates to the result of the second derivative, it is also implied that the kind of return is related to the efficient frontier format. Figure 2 presents two examples of increasing and differentiable functions, so $f \wedge^{\prime}>0$. Examples (2A) and (2B) present different concavities, therefore, their second derivatives have different symbols. According to the fundamentals of Calculus, an upward concave curve has a positive second derivative and a downward concave curve has a negative second derivative.

By relating these characteristics (equation 8), it can be concluded that: 

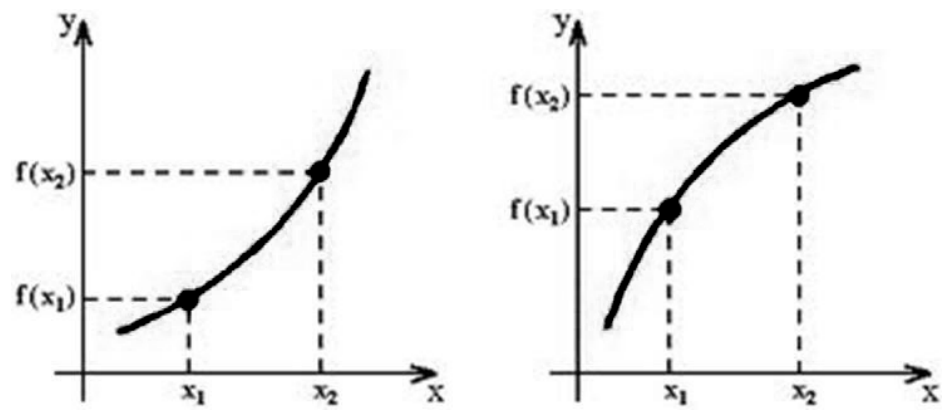

Figure 2 - Example of Upward (A) and Downward (B) Concave Differentiable Curves.

Source: The authors.

- A concave upward function presents global increasing returns to scale (GIRS) and the variation of marginal productivity is always positive;

- A concave downward function presents global decreasing returns to scale (GDRS) the variation of marginal productivity is always negative.

\subsection{Algebraic characteristics of downward and upward concave curves}

This sub-section aims to translate the definitions presented in the previous topic into algebraic expressions which may define the upward and downward concave curves.

A line segment that joins two points in space is the set of all convex combinations of these points. In Figure 3, the set between two points, $x_{1}$ and $x_{2}$, is given by the interval $I_{x 1,2}=\left[x_{1}, x_{2}\right]$, that is, all the convex combinations of $x_{1}$ and $x_{2}$, by:

$$
\left.I_{x 1 \times 2} \equiv\{1-t)_{1}+t x_{2}: 0 \leq t \leq 1\right\}
$$

In a strict convex combination, $x_{1}$ and $x_{2}$ are excluded from the set, therefore, the convex combination coefficients are different from zero and one, according to:

$$
\left.I_{x 1 x 2}^{*} \equiv\{1-t) x_{1}+t x_{2}: 0<t<1\right\}
$$

The set of points in graph $f(x)$ restrict to $I_{x 1,2}$ :

$$
\left\{(1-t)_{1}+t x_{2}, f\left((1-t) x_{1}+t x_{2}\right) ; 0 \leq t \leq 1\right\}
$$

Therefore, the secant line which joins points $\left(x_{1},\left(x_{1}\right)\right)$ and $\left(x_{2}, f\left(x_{2}\right)\right)$ is given by:

$$
(1-t)\left(x_{1},\left(x_{1}\right)\right)+\left(x_{2}, f\left(x_{2}\right)\right)=\left((1-t) x_{1}+t x_{2},(1-t) f\left(x_{1}\right)+t f\left(x_{2}\right)\right), t \in[0,1]
$$

A function is said to be concave upward, as in Figure 3, if the secant line that joins $x_{1}$ to $f\left(x_{1}\right) x_{2}$ to $f\left(x_{2}\right)$ is always above the curve, according to:

$$
(1-t) f\left(x_{1}\right)+t f\left(x_{2}\right) \geq f\left((1-t) x_{1}+t x_{2}\right)
$$




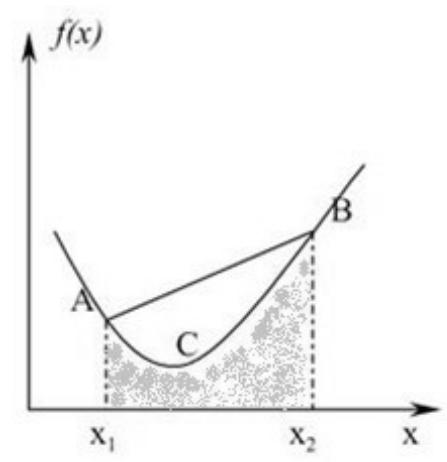

Figure 3 - Upward Concave Function.

Source: The authors.

It may be concluded that a function $\mathrm{f}$ is upward concave if, and only if, any secant line which joins two points in the function graph is above the curve. However, a function $\mathrm{f}$ is upward concave if, and only if, $-f$ is downward concave function. Therefore, a function is downward concave if, and only if, any secant line which joins two points in the function is below the curve (BORTOLOSSI, 2002).

When the analyzed function is an efficient production frontier, it is known that there is a PPS called $T$, as shown in the blue area in Figure 3 and defined in equation (1). To define the efficient frontier convexity, consider that:

Proposition 1. The line segment represented by a strict convex linear combination of two points $A$ and $B$ does not belong to the PPS T, which refers to an upward concave efficient production frontier.

Definition 1. By knowing that, as presented in (11), a line segment with a strict linear combination is defined by a line segment with an interval $I_{x_{1}, x_{2}}^{*}$, such that:

$$
(1-t) f\left(x_{1}\right)+t f\left(x_{2}\right) \geq f\left((1-t) x_{1}+t x_{2}\right)
$$

as shown in equation (13), so $I_{x_{1} x_{2}}^{*} \notin T$.

Similarly:

Proposition 2. The line segment represented by a convex linear combination of two points $A$ and $B$ belongs to the PPS T, which refers to a downward concave efficient production frontier.

Definition 2. By knowing that, as presented in (10), a linear combination is defined by a line segment with an interval $I_{x_{1}, x_{2}}$, such that

$$
(1-t) f\left(x_{1}\right)+t f\left(x_{2}\right) \geq f\left((1-t) x_{1}+t x_{2}\right)
$$

therefore $I_{x_{1} x_{2}} \in T$. 


\subsection{BCC efficient frontier format and global returns to scale analysis}

The DEA BCC model is based on the identification of limits on the multiple hyperplanes contained in a convex PPS (Thanassoulis, 2001). Thus, considering a multiple input $(X)$ and output $(Y)$ production, $T$ is defined as the PPS, where $(X, Y) \| Y$ may be produced with an input $X$.

The PPS convexity of the BCC model is ensured by assumption 1, expressed in (15) (Banker et al., 1984):

Considering that:

$$
(X, Y) \in T \text { and }\left(X^{\prime}, Y^{\prime}\right) \in T, \text { so }\left(\lambda X+(1-\lambda) X^{\prime}, \lambda Y+(1-\lambda) Y^{\prime}\right) \in T
$$

for any $\lambda \in[0,1]$

Therefore, the PPS is given by (16):

$$
T_{B C C} \equiv\left\{(X, Y) \| X \geq \sum_{j=1}^{n} \lambda_{j} X_{j}, Y \leq \sum_{j=1}^{n} \lambda_{j} Y_{j}, \sum_{j=1}^{n} \lambda_{j}=1, \lambda_{j} \geq 0\right\}
$$

The viable production region in the DEA BCC model is restricted by a frontier with variable returns to scale, since the efficient DMUs present different AP in different scales of its frontier. The line segment in interval $I_{x_{1} x_{2}}$, which joins two points of the DEA BCC efficient frontier, presents characteristics of a downward concave frontier, as shown in Proposition 2, such that $(1-t)\left(x_{1}\right)+t f\left(x_{2}\right) \leq f\left((1-t) x_{1}+t x_{2}\right)$.

Therefore $I_{x_{1} x_{2}} \in T_{B C C}$.

Thus, even though it is not differentiable, the BCC frontier is characterized as a downward concave frontier (Benicio \& Soares de Mello, 2015).

Considering the DEA BCC frontier is concave downward together with the concepts presented in Section 2, we can conclude that the efficient DMU of the model may be analyzed according to two aspects (Benicio, 2015):

A. The average productivity: The efficient BCC DMUs present different average productivity compared with each other; therefore, different local returns to scale are observed.

Then, the analysis suggested by the BCC model identifies the kind of local return to scale, given that it varies along the frontier. In other words, when the model results in a local increasing return, for example, it means that there has been an increase in the average productivity. Similarly, when the model results in a local decreasing return, it means that there has been a decrease in the average productivity.

B. The marginal productivity: The efficient BCC DMUs present variation in their marginal productivity throughout the frontier: the higher the number of inputs, the lower the marginal productivity. In other words, comparing a high scale efficient BCC DMU to another which is also 


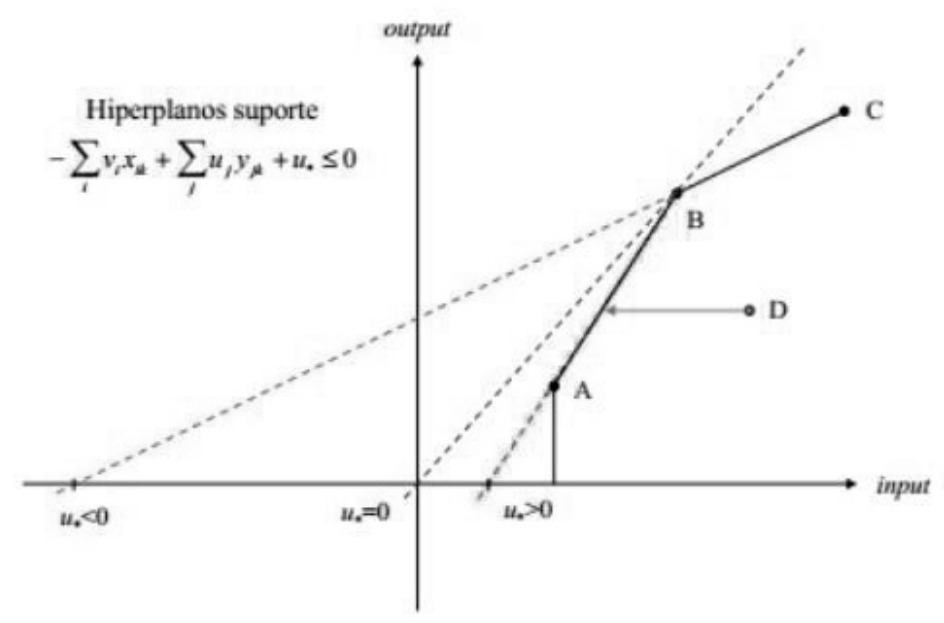

Figure 4 - DEA BCC Scale Factor sign oriented to input.

Source: Soares de Mello et al. (2008).

efficient, with a shorter scale, necessarily the DMU with more inputs presents a lesser marginal productivity.

In conclusion, the DEA BCC model creates a downward concave efficient frontier (as seen in Figure 4) and the efficient DMUs do not need to present the same productivity (Panzar \& Willig, 1977; Baumol et al., 1982).

The verification of the return to scale held by the DEA BCC model is based on the local concept. The analysis of the kind of return to scale is given by the results obtained in the values of the variables $u^{*}$ and $v^{*}$, called scale variables. In the model which aims at inputs (Figure 4), if $u^{*}$ is positive, its representation is given by the red dotted line and indicates a local increasing return to scale; that is, an average productivity gain was observed. When $u^{*}$ is negative, its representation is the green dotted line and indicates a local decreasing return to scale; that is, an average productivity loss was observed. If $u^{*}$ is void, there is a local constant return to scale, represented by the blue dotted line (Soares de Mello et al., 2008).

Although, a downward concave frontier presents a GDRS, for this reason, the marginal productivity decreases along the efficient frontier (Dulá, 2002; Simon \& Blume, 1994). There is no reason to analyze the variable returns to scale under a single kind of frontier. The option of an efficient frontier that ensures an increasing marginal productivity is not seen in the specialized literature, and it must be explored by researchers.

\section{EXAMPLE OF A CONCAVE UPWARD EFFICIENT FRONTIER}

This section aims to simulate an efficient concave upward frontier. The efficient frontier empirically proposed here presents a GIRS and its results are compared with the efficient DEA BCC 
Table 1 - Example Data, CCR and BCC efficiency (input oriented).

\begin{tabular}{c|c|c|c|c}
\hline DMU & Input & Output & CCR & BCC \\
\hline 1 & 7 & 25 & 0.2386 & 1 \\
\hline 2 & 11 & 59 & 0.3583 & 0.8246 \\
\hline 3 & 20 & 120 & 0.4008 & 0.6393 \\
\hline 4 & 22 & 130 & 0.3947 & 0.6088 \\
\hline 5 & 32 & 251 & 0.524 & 0.6489 \\
\hline 6 & 39 & 339 & 0.6471 & 0.7464 \\
\hline 7 & 45 & 367 & 0.5448 & 0.6184 \\
\hline 8 & 49 & 395 & 0.5385 & 0.6027 \\
\hline 9 & 52 & 536 & 0.6886 & 0.7331 \\
\hline 10 & 58 & 606 & 0.698 & 0.7308 \\
\hline 11 & 60 & 546 & 0.6079 & 0.6455 \\
\hline 12 & 62 & 928 & 1 & 1 \\
\hline 13 & 78 & 1,135 & 0.9721 & 1 \\
\hline 14 & 89 & 1,163 & 0.873 & 0.9131 \\
\hline 15 & 102 & 1,272 & 0.8331 & 0.9214 \\
\hline 16 & 112 & 1,382 & 0.8243 & 0.9538 \\
\hline 17 & 129 & 1,572 & 0.8141 & 1 \\
\hline 18 & 138 & 1,603 & 0.776 & 1 \\
\hline & & & \multicolumn{2}{|c}{}
\end{tabular}

Source: The authors.

frontier. Therefore, along the efficient frontier with increasing marginal productivity the amount of inputs also increases. This frontier presents the following characteristics:

- It is upward concave and

- Its marginal productivity increases throughout the frontier.

The proposed case study will analyze the education sector, more specifically, the efficiency in university management; in other words, the ability of the staff to manage their students. Eighteen higher education units of the same company in Brazil have been analyzed. The input is the number of 40-hour employees in March 2016 and the output is the total amount of students registered in March 2016.

Table 1 describes the model data, as well as the CCR and BCC efficiency results (input oriented). As seen above, the efficient CCR DMU is 12 . The DMUs $1,12,13,17$, and 18 were considered BCC efficient. As shown before, the Table 2 confirms that the marginal productivities of the efficient BCC DMUs are decreasing.

However, one may observe in Table 3 that there are DMUs which present increasing marginal productivity; such as DMUs 2 that there are DMUs which present. 
Table 2 - Marginal productivities of the efficient BCC DMUs.

\begin{tabular}{c|c|c|c|c|c}
\hline DMU & Input & Output & CCR & BCC & PMg \\
\hline 1 & 7 & 25 & 0.2386 & 1 & - \\
\hline 12 & 62 & 928 & 1 & 1 & 16.41 \\
\hline 13 & 78 & 1,135 & 0.9721 & 1 & 12.93 \\
\hline 17 & 129 & 1,572 & 0.8141 & 1 & 11.17 \\
\hline 18 & 138 & 1,603 & 0.776 & 1 & 3.44 \\
\hline
\end{tabular}

From the perspective of the GIRS, DMUs 2, 5, 6, and 9 should be considered efficient. These DMUs presented increasing marginal productivity and a positive slope.

In Figure 5 we could represent the both results: the first one, from Table 2, that presents DMUs 1, 12, 13, 17 and 18 as efficient (BCC frontier); and the second ond, that presents DMUs 2, 5, 6, 9 and 12 as efficient (FConc - upward concave frontier).

Graphically it is clear that the BCC model makes a downward concave envelope frontier (blue line), ensuring a decreasing marginal productivity; thus, a GDRS. The DMUs which compose the red line are part of an (FConc) and have increasing marginal productivity; therefore, a GIRS. This kind of efficient frontier is still untapped by DEA.

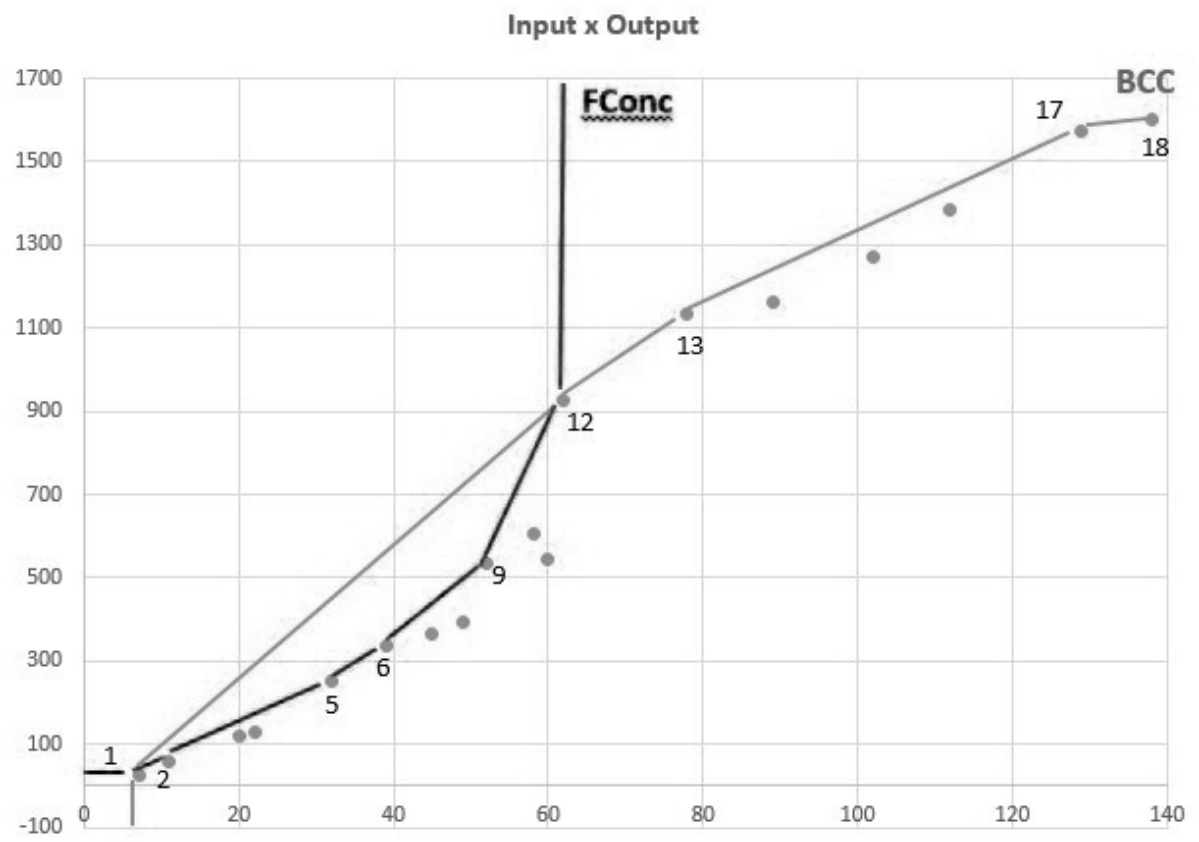

Figure 5 - DEA BCC Efficient Frontiers and Upward Concave Efficient Frontier (FConc). Source: The authors. 
Table 3 - Marginal productivities of all DMUs.

\begin{tabular}{c|c|c|c|c|c}
\hline DMU & Input & Output & CCR & BCC & PMg \\
\hline 1 & 7 & 25 & 0.2386 & 1 & - \\
\hline 2 & 11 & 59 & 0.3583 & 0.8246 & $\mathbf{8 , 5}$ \\
\hline 3 & 20 & 120 & 0.4008 & 0.6393 & $\mathbf{6 , 7 7 7 7 7 7 8}$ \\
\hline 4 & 22 & 130 & 0.3947 & 0.6088 & $\mathbf{5}$ \\
\hline 5 & 32 & 251 & 0.524 & 0.6489 & $\mathbf{1 2 , 1}$ \\
\hline 6 & 39 & 339 & 0.6471 & 0.7464 & $\mathbf{1 2 , 5 7 1 4 2 9}$ \\
\hline 7 & 45 & 367 & 0.5448 & 0.6184 & $\mathbf{4 , 6 6 6 6 6 6 7}$ \\
\hline 8 & 49 & 395 & 0.5385 & 0.6027 & $\mathbf{7}$ \\
\hline 9 & 52 & 536 & 0.6886 & 0.7331 & $\mathbf{4 7}$ \\
\hline 10 & 58 & 606 & 0.698 & 0.7308 & $\mathbf{1 1 , 6 6 6 6 6 7}$ \\
\hline 11 & 60 & 546 & 0.6079 & 0.6455 & $\mathbf{- 3 0}$ \\
\hline 12 & 62 & 928 & 1 & 1 & $\mathbf{1 9 1}$ \\
\hline 13 & 78 & 1,135 & 0.9721 & 1 & $\mathbf{1 2 , 9 3}$ \\
\hline 14 & 89 & 1,163 & 0.873 & 0.9131 & $\mathbf{2 , 5 4}$ \\
\hline 15 & 102 & 1,272 & 0.8331 & 0.9214 & $\mathbf{8 , 3 8}$ \\
\hline 16 & 112 & 1,382 & 0.8243 & 0.9538 & $\mathbf{1 1}$ \\
\hline 17 & 129 & 1,572 & 0.8141 & 1 & $\mathbf{1 1 , 1 7}$ \\
\hline 18 & 138 & 1,603 & 0.776 & 1 & $\mathbf{3 , 4 4}$ \\
\hline
\end{tabular}

Source: The authors.

This example exposes the complementarity of the frontiers and the need to incorporate GIRS in the analytical methodology of the DEA model.

\section{CONCLUSION}

We presented different types of returns to scale in the economic literature and incorporated their concepts in the analysis of DEA. This has shown frontier formats which can be associated with different returns to scale and compared them with those currently provided by the existing DEA models.

It became evident that, in the DEA literature, the variable returns are checked from the perspective of local returns to scale, therefore analyzing only one case of variable marginal productivity. Because of this, the analysis of variable returns from the perspective of the GIRS has been neglected by the DEA literature.

In this regard, the importance of this research was mainly because of the delimitation of the scope of action of the BCC DEA model, and it was revealed that the model is not able to identify DMUs with lower inputs (than the efficient CCR DMU) and which have increasing marginal productivity; therefore, these should be considered efficient. Such evidence does not characterize an error of the BCC model, which complies with analyzing the variable local returns to scale 
in a frontier with GDRS. Nevertheless, this evidence indicates the need to recognize additional models that could achieve complementary results, such as in the analysis of variable local returns to scale in a frontier with GIRS (exemplified by the case study).

Although the BCC frontier shows a benevolence over CCR and considers efficient DMUs with lower productivity than efficient CCR; there are cases that the BCC downward border neglects DMUs that have marginally increasing productivity and therefore should be considered efficient as well.

Therefore, the importance of considering a concave frontier in the DEA model lies in the fact that this new frontier can identify DMUs (generally of a smaller scale than the efficient CCR DMU) that present increasing marginal productivity but are not considered efficient in the model BCC.

Given this, it is observed that both frontiers - BCC and FConc -, with the evolution of the studies, can be used in a complementary way, in order to better understand the behavior and characteristics of the efficient DMUs.

The main challenge arising from this research is to propose a complementary model to the DEA $\mathrm{BCC}$, which presents an upward concave efficient frontier and, therefore, a GIRS.

\section{REFERENCES}

[1] BANKer RD, CHANG H \& COOPER WW. 1996. Equivalence and implementation of alternative methods for determining returns to scale in data envelopment analysis. European Journal of Operational Research, 89(3): 473-481.

[2] Banker RD, Charnes A \& Cooper WW. 1984. Some models for estimating technical and scale inefficiencies in data envelopment analysis. Management Science, 30(9): 1078-1092.

[3] Banker RD, CoOper WW, Seiford LM, Thrall RM \& ZhU J. 2004. Returns to scale in different DEA models. European Journal of Operational Research, 154(2): $345-362$.

[4] BANKer RD \& Thrall RM. 1992. Estimation of returns to scale using data envelopment analysis. European Journal of Operational Research, 62: 74-84.

[5] Baumol WJ, Panzar JC \& Willig RD. 1982. Contestable markets. New York: Harcourt Brace Jovanovich.

[6] Benicio J. 2015. Construção da Fronteira de Eficiência Não Paramétrica com Retornos Crescentes de Escala. Ph.D. thesis. Department of Production Engineering, Universidade Federal Fluminense. Niterói, RJ.

[7] Benicio J \& SoARes de Mello JC. 2015. Productivity analysis and variable returns of scale: DEA Efficiency Frontier Interpretation. Procedia Computer Science, 55: 341-349.

[8] Blaug M. 1962. Economic Theory in Retrospect. London: Helnemmann. 
[9] Charnes A \& Cooper WW. 1962. Programming with linear fractional functionals. Naval Research logistics quarterly, 9(3-4): 181-185.

[10] Charnes A \& CoOper WW. 1985. Preface to topics in data envelopment analysis. Annals of Operations Research, 2: 59-94.

[11] Charnes A, Cooper WW, Lewin AY \& Seiford LM. 1995. Data Envelopment Analysis: Theory, Methodology and Applications. Boston: Kluwer Academic Publishers.

[12] Charnes A, Cooper WW \& Rhodes E. 1978. Measuring the efficiency of decision making units. European Journal of Operational Research, 2(6): 429-444.

[13] Charnes A, Gallegos A \& Li H. 1996. Robustly efficient parametric frontiers via multiplicative DEA for domestic and international operations of the Latin American airline industry. European Journal of Operational Research, 88(3): 525-536.

[14] Cooper WW, Seiford LM \& Tone K. 2000. Data Envelopment Analysis: A Comprehensive Text with Models, Applications, References and DEA-Solver Software. USA: Kluwer Academic Publishers. 1-40 pp.

[15] Debreu G. 1959. Theory of value: An axiomatic analysis of economic equilibrium. Cowles Foundation Monograph No. 17. Cowels Foundation for Research in Economics: Yale University.

[16] Dulá JH. 2002. Computations in DEA. Pesquisa Operacional, 22(2): 165-182.

[17] Färe R, Grosskopf S, Norris M \& Zhang Z. 1994. Productivity Growth, Technical Progress, and Efficiency Change in Industrialized Countries. American Economic Review, 84(1): 66-83.

[18] Färe R \& LOVEll CAK. 1978. Measuring the technical efficiency of production. Journal of Economic Theory, 19(1): 150-162.

[19] Farrell MJ. 1957. The measurement of productive efficiency. Journal of the Royal Statistical Society: Series A, Part 3, pp. 253-290.

[20] Fried HO, KNOx LOVEll CA \& SChmidT SS. 2008. The measurement of productive efficiency and productivity growth. Oxford University Press.

[21] HART N. 1990. Increasing Returns and Economic Theory: Marshall's Reconciliation Problem. Campbelltown: University of Western Sydney.

[22] KATZNER DW. 2006. An introduction to the economic theory of market behavior: microeconomics from a Walrasian perspective. Edward Elgar Publishing.

[23] Milioni AZ \& Alves LB. 2013. Ten years of research on parametric data envelopment analysis. Pesquisa Operacional, 33(1): 89-104. 
[24] MiYAZAKi H. 2001. Scale Economies and Homogeneity. Microeconomics Lecture Supplements. Departament of Economics, Ohio State University.

[25] Panzar JC \& Willig RD. 1977. Economies of Scale in Multi-Output Production. The Quarterly Journal of Economics, 91: 481-493.

[26] Pastor JT, Ruiz JL \& Sirvent I. 1999. An enhanced DEA Russell graph efficiency measure. European Journal of Operational Research, 115: 596-607.

[27] Petranka J. 2012. Intermediate Microeconomics: The Science of Choice. Paperback.

[28] Pigou AC. 1910. Producers' and consumers'surplus. The Economic Journal, 20.

[29] Pindyck RS \& RUBinfeld DL. 2002. Microeconomia. 5 ed.. So Paulo: Prentice Hall.

[30] Podinovski VV. 2004. Local and global returns to scale in performance measurement. Journal of the Operational Research Society, 55(2): 170-178. part Special Issue: Intelligent Management Systems in Operations.

[31] QUINZII M. 1992. Increasing returns and efficiency. Oxford University Press on Demand.

[32] RICARDO D. 1951. Works and Correspondence. Cambridge: Cambridge University Press.

[33] Simon CP \& Blume L. 1994. Mathematics for Economists. vol. 7. London: W. W. Norton \& Company.

[34] Smith A. 1976. An Inquiry into the Nature and Causes of the Wealth of Nations. The Glasgow Edition of the Works and Correspondences of Adam Smith. Oxford University Press.

[35] Soares de Mello J, Angulo Meza L, Gomes EG \& Biondi Neto L. 2005. Curso de análise de envoltória de dados. XXXVII Simpósio Brasileiro de Pesquisa Operacional, Gramado.

[36] Soares de Mello JC, Angulo Meza L, Gomes EG \& Leta FR. 2008. DeA advanced models for geometric evaluation of used lathes. WSEAS Transactions on Systems, 7(5): 510-520.

[37] Souza GS \& Gomes EG. 2013. Scale of operation, allocative inefficiencies and separability of inputs and outputs in agricultural research. Pesquisa Operacional, 33(3): 399-415.

[38] Sueyoshi T. 1999. DEA duality on returns to scale (RTS) in production and cost analyses: an occurrence of multiple solutions and differences between production-based and cost-based RTS estimates. Management Science, 45(11): 1593-1608.

[39] Talluri S. 2000. Data envelopment analysis: models and extensions. Production/Operations Management, pp. 8-11. 
[40] Thanassoulis E. 2001. Introduction to the Theory and applications in Data Envelopment Analysis: A Foundation Text with Integrated Software. Boston: Kluwer Academics Publishers.

[41] VARIAN H. 1992. Microeconomic analysis. London: W. W. Norton \& Company. 